\title{
A new conceptual framework for the integrated neural control of locomotor and sympathetic function: implications for exercise after spinal cord injury
}

\begin{tabular}{|r|l|}
\hline Journal: & Applied Physiology, Nutrition, and Metabolism \\
\hline Manuscript ID & apnm-2018-0310.R1 \\
\hline Manuscript Type: & Review \\
\hline $\begin{array}{r}\text { Date Submitted by the } \\
\text { Author: }\end{array}$ & 20 -Jul-2018 \\
\hline $\begin{array}{r}\text { Complete List of Authors: } \\
\text { Is the invited manuscript } \\
\text { for consideration in a } \\
\text { Special Issue? : }\end{array}$ & $\begin{array}{l}\text { Cowley, Kristine; University of Manitoba College of Medicine, } \\
\text { Physiology and Pathophysiology }\end{array}$ \\
\hline Keyword: & $\begin{array}{l}\text { autonomic nervous system < nervous system, locomotion }< \\
\text { locomotion, endurance training < exercise, thermoregulation, } \\
\text { exercise metabolism < exercise }\end{array}$ \\
\hline \multicolumn{2}{|}{} \\
\hline
\end{tabular}


A new conceptual framework for the integrated neural control of locomotor and sympathetic function: implications for exercise after spinal cord injury

\author{
Kristine C Cowley \\ Department of Physiology and Pathophysiology, \\ Rady Faculty of Health Sciences, University of Manitoba \\ Winnipeg, Manitoba CANADA R3E 0J9
}

Running head title: The link between rhythm production and sympathetic support in exercise Correspondence should be addressed to:

Kristine C Cowley

Spinal Cord Research Centre, Department of Physiology and Pathophysiology

Room 405, Basic Medical Sciences Building

Rady Faculty of Medicine

University of Manitoba

745 Bannatyne Avenue

Winnipeg, Manitoba

CANADA R3E 0J9

Phone: (204) 789-3305

Fax: (204) 789-3934

email: Kristine.Cowley@umanitoba.ca 


\section{Abstract}

All mammals, including humans, are designed to produce sustained locomotor movements. Many higher centres are involved in movement, but ultimately these centres act upon a core 'rhythm-generating' network within the brainstem-spinal cord. In addition, endurance-based locomotor exercise requires sympathetic neural support to maintain homeostasis and to provide needed metabolic resources. This review focuses on the roles and integration of these two neural systems. Part I reviews the cardiovascular, thermoregulatory and metabolic functions under spinal sympathetic control as revealed by spinal cord injury at different levels. Part II examines the integration between brainstem-spinal sympathetic pathways and the neural circuitry producing motor rhythms. In particular, the rostroventral medulla (RVM) contains the neural circuitry that: 1) integrates heart rate, contractility and blood flow in response to postural changes; 2) initiates and maintains cardiovascular adaptations for exercise; 3) provides direct descending innervation to pre-ganglionic neurons innervating the adrenal glands, white adipose tissue, and tissues responsible for cooling the body; 4) integrates descending sympathetic drive for energy substrate mobilization (lipolysis); and 5) is the relay for descending locomotor commands arising from higher brain centres. A unifying conceptual framework is presented, in which the RVM serves as the final descending supraspinal 'exercise integration centre' linking the descending locomotor command signal with the metabolic and homeostatic support needed to produce prolonged rhythmic activities. The role and rationale for an ascending sympathetic and locomotor drive from the lower to upper limbs within this framework is presented. Examples of new research directions based on this unifying framework are discussed.

Key words: autonomic nervous system, exercise metabolism, thermoregulation, locomotion, endurance training 


\section{Introduction}

Humans are designed to produce sustained rhythmic locomotor activities, such as cycling, skiing and running. Sympathetic support to maintain homeostasis and provided needed metabolic resources are critical for these types of endurance-based exercise. However, key aspects of the integration between the neural circuitry generating locomotor movements and those mediating the needed sympathetic support to maintain rhythmic movement remain unknown.

We know that the cortex initiates movement by acting on multiple brain sites and upon a core rhythm-generating circuitry within the brainstem-spinal cord. The parapyramidal region of the medulla is the final supraspinal site that relays the descending spinal command signal to produce rhythmic locomotor activity. Our ability to sustain rhythmic exercise such as cycling or running relies on the resources provided by the brainstem-spinal sympathetic nervous system. This review connects two research domains: sympathetic autonomic support for exercise and brainstem-spinal locomotor rhythm generation and coordination. In Part I we review the roles and physiology of the brainstem-spinal sympathetic system, revealed by damage at different levels of the neuraxis after spinal cord injury (SCI). Acute and training-based limitations caused by loss of cardiovascular, thermoregulatory and metabolic function are reviewed. Part II focuses on the neural circuitry that produces the most basic components of movement, that of rhythmic alternation between flexors and extensors, left and right and the lower and upper body. This brainstem-spinal locomotor rhythm-generating network, and its integration with the sympathetic neural support systems will be examined. A conceptual framework will be introduced, positing that neurons within the rostroventral medulla (RVM) serve to integrate the descending locomotor command signal with the sympathetic drive needed to support prolonged rhythmic (endurance- 
based) movements. The propriospinal system generating locomotor rhythms will be described, as will its relationship to spinal sympathetic preganglionic neurons providing metabolic support and thermoregulation. The implications for future research exploring the neural mechanisms mediating the integration between sympathetic autonomic function and locomotor rhythm production are addressed. Finally, clinical research strategies to improve performance after SCI within this conceptual framework are mentioned.

\section{Resting and exercise-based impairments in cardiovascular, thermoregulatory and metabolic functions caused by spinal cord injury at different levels}

Figure 1 is a schematic showing the spinal levels that provide sympathetic neural input to key tissues and organs needed to support exercise. Sympathetic pre-ganglionic neurons within the intermediolateral cell column are distributed from thoracic (T1) to the rostral lumbar $(\sim \mathrm{L} 2)$ spinal levels. It is impairment to this component of the autonomic nervous system that most limits exercise performance after SCI. In particular, function is impaired by limited or absent cardiovascular, thermoregulatory, and energy substrate mobilization functions.

\section{A. Cardiovascular control: spinal cord injury and performance limitations}

\section{Sympathetic activation of the heart is absent in tetraplegia, reduced in high thoracic paraplegia, and fully functional with mid-thoracic level paraplegia}

At low activity levels, the autonomic nervous system increases heart rate (HR) by reducing basal parasympathetic activity. As activity levels increase, descending medullary-spinal fibres activate pre-ganglionic sympathetic neurons in the upper thoracic spinal cord, which excite sympathetic 
post-ganglionic neurons innervating the heart. The sympathetic innervation of the heart arises from pre-ganglionic neurons within thoracic (T) T1 to T5. Sympathetic activation at these spinal levels increase HR, contractility and stroke volume (Loewy and Spyer 1990). Therefore, in 'complete' injury at cervical (C) C8 or above, functional sympathetic innervation is absent and peak HR during maximal exercise is limited [Table 1, 110 - $130 \mathrm{bpm}$; reviewed in (Bhambhani 2002)]. Injury within rostral thoracic regions reduces sympathetic control of the heart, whereas relatively normal HR and contractility is present with injury below T3-5 (Hopman et al. 1993).

\section{Impairment to exercise-induced sympathetically-mediated changes in blood pressure and blood-flow to active and inactive tissues after spinal cord injury}

Normally during exercise systemic vasoconstriction to increase mean arterial pressure is mediated by circulating catecholamines released from the adrenal glands, along with vasomotor innervation of muscle vascular beds and internal organs. After SCI, a range of dysfunction occurs, depending on level of injury. Cervical injury above $\mathrm{T} 1$ results in drastic reduction in catecholamine levels even compared to high-level paraplegia injury (T1 - T4; Table 1).

Catecholamine release is absent in athletes with tetraplegia, even during half-marathons (Ogawa et al. 2014). Smaller differences in performance and catecholamine levels are observed with mid compared to low thoracic SCI [Table 1; (Schmid et al. 1998)]. In addition, the direct sympathetic innervation of skeletal muscle arteries originate at and below T1 spinal levels [Figure 1, (Loewy and Spyer 1990)]. The main sympathetic pre-ganglionic neuronal input to renal and splanchnic regions as well as the adrenal glands arises from mid-thoracic levels (Sato 1987, Strack et al. 1988, Loewy and Spyer 1990). As a result, typical exercise-induced reductions in portal vein 
blood flow to splanchnic regions do not occur with injury above $\mathrm{T} 7$ but are present in those with low thoracic SCI (Thijssen et al. 2009).

In parallel with systemic vasoconstriction, factors released in active tissues mediate local vasodilation [sympatholysis (Thomas and Segal 2004)]. Sympatholysis is mediated, at least in part, by release of the vasodilator nitric oxide in response to increasing endothelial shear stress (Thomas and Victor 1998, Green et al. 2014). Normally, these coordinated vascular events can increase blood flow to active muscle and skin by 5-fold while reducing blood flow to the splanchnic region and kidneys to as little as 2-5\% of total blood flow in exercise (Wade and Bishop 1962). People with SCI show similar femoral artery vasodilation responses to locally applied nitric oxide as controls, suggesting an intact peripheral response in leg vasculature (Kooijman et al. 2008). Thus, although normal local endothelial tissue responses may function after SCI, sympathetically mediated blood flow regulation would be absent in tetraplegia and reduced in thoracic level injury.

\section{Peak heart rate, oxygen uptake, and power and associated training adaptations are blunted after tetraplegia compared to paraplegia-level injury}

Acute exercise responses measured in endurance-trained elite athletes with different levels of SCI best illustrate the effects of the impaired sympathetic function. Complete absence of sympathetic neural activation, as occurs after cervical injury, reduces peak absolute power output and peak absolute and relative oxygen uptake by about half when compared to endurance athletes with paraplegia level injury [Table 1, (Bhambhani 2002)]. 
With training, only relatively small improvements in peak physical capacity $\left(\sim 5 \mathrm{ml} \cdot \mathrm{kg}^{-1} \cdot \mathrm{min}^{-1}\right.$ in $\mathrm{VO}_{2 \text { peak }}$ ) have been reported in elite-level trained athletes with tetraplegia compared to untrained persons with tetraplegia (Eriksson et al. 1988). In contrast, it may be possible to double peak relative oxygen consumption with aerobic training in low-level paraplegia $[40.4+/-5.5$ versus $21.23+/-4.7 \mathrm{ml} \cdot \mathrm{kg}^{-1} \cdot \mathrm{min}^{-1}$, (Lovell et al. 2012)]. The fact that relatively large samples of persons with tetraplegia $(\mathrm{n}=50)$ show a similar and small range of peak performance $\left[10.8\right.$ to $15.2 \mathrm{ml} \mathrm{kg}^{-}$ ${ }^{1} \cdot \mathrm{min}^{-1}$, (Simard et al. 1993)], with peak $\mathrm{VO}_{2}$ values similar to that of Paralympic-level athletes (Eriksson et al., 1988), suggests that injury level is the largest determinant of peak performance after cervical SCI, regardless of training status. These findings highlight the critical contributions of the sympathetic autonomic nervous system in training adaptations to endurance exercise.

\section{B. Temperature regulation: cooling after spinal cord injury and performance limitations}

\section{Functional spinal neuroanatomy of thermoregulation}

A person can only tolerate about $4^{\circ} \mathrm{C}$ in core temperature change without impairing physical and mental performance. Sweating is critical for the human body to rid itself of excess heat (McArdle et al. 2001). The innervation of sweat glands over most of the body is via sympathetic innervation arising from the thoracic and lumbar spinal cord (T1 - L2). The pattern of innervation generally follows the cutaneous dermatomes over the body (Nathan and Smith 1987). However, heat-based activation of sweat glands for the skin that correspond to the head, neck and arms requires sympathetic innervation via the superior cervical ganglion which arises from sympathetic neurons at and below the T1 thoracic level [T1 - T5, (Nathan and Smith 1986)]. Therefore, all persons with 'complete' injury at C8 or above will be unable to sweat in 
response to heat. For those with paraplegia, the innervation of skin sweat glands will be intact until the level of the SCI, and absent below.

\section{Changes in body surface and core temperature at rest after spinal cord injury reveal the poikilothermic state of persons with tetraplegia}

In 1958, Guttman and colleagues presented a striking demonstration of the absence of temperature regulating mechanisms in response to environmental heat or cold after cervical SCI. In particular, seven men were exposed, naked, to two hours of cool $\left(18^{\circ} \mathrm{C}\right)$ or warm $\left(36^{\circ} \mathrm{C}\right)$ temperature. Those with injury above $\mathrm{T} 1 \mathrm{had}$ decreased core and skin temperature at cool temperatures and increased skin and core temperatures at warm temperatures. For those with injury below T1, core temperature was well maintained while skin temperature tended to follow lesion level: finger temperature could be maintained (and was different from core) whereas toe temperature tended to follow the ambient conditions (Guttmann et al. 1958). Thus, in resting conditions, those with tetraplegia essentially become poikilotherms; severely limited in their ability to either cool in response to warm ambient conditions or to warm in response to cool ambient conditions (Altus et al. 1985, Khan et al. 2007, Handrakis et al. 2017).

\section{Core temperature regulation during exercise in warm conditions absent in tetraplegia, and inversely related to level of injury in paraplegia}

Those with complete cervical injury have no capability to activate compensatory sympathetic responses during exercise in warm environments and show continuous increases in core temperature (Price and Campbell 1999). Partial innervation of the sympathetic spinal autonomic system imparts some capability for appropriate thermoregulation during exercise, but the absence 
of local vasodilation and sweating that normally contributes to whole body cooling during exercise is missing below the level of injury (Price 2006, Griggs et al. 2015). Athletes with lowlevel paraplegia (below T6) demonstrate similar responses to able-bodied controls when performing prolonged arm crank ergometry at $35^{\circ} \mathrm{C}$, including reduced stroke volume $(\sim 20 \%)$, and unaltered oxygen uptake and cardiac output between 15 and 45 minutes of exercise at $40 \%$ $\mathrm{VO}_{2 \text { peak. }}$ Those with injury between $\mathrm{T} 2$ and $\mathrm{T} 6$ additionally demonstrated a reduction in cardiac output (Hopman et al. 1993).

\section{Substrate mobilization: spinal cord injury and performance limitations}

\section{Energy metabolism during exercise in tetraplegia shows a reduced reliance on free fatty acids compared to paraplegia-level injury}

Historically, the initiation of white adipose tissue (WAT) lipolysis for free fatty acid release was attributed to circulating catecholamines activated by sympathetic drive to the adrenal medulla. However, as discussed in Part II, there is an additional direct neuronal pathway between the rostroventral medulla, spinal sympathetic pre-ganglionic neurons below T8 and white adipose tissue [reviewed in (Bartness et al. 2010)]. High intensity, short duration exercise relies on intramuscular stores of ATP and creatinine; with increasing duration there is a greater proportion of energy provided by aerobic metabolism of carbohydrates and fats (McArdle et al. 2001). Fat oxidation contributes the greatest proportion of needed energy at moderate levels of exercise $\left(\sim 55-65 \%\right.$ peak $\left.\mathrm{VO}_{2}\right)$; carbohydrate metabolism is the largest contributor with intensities above $80-85 \%$ of $\mathrm{VO}_{2 \text { peak }}$ (Romijn et al. 1993). Similar to able-bodied controls, those with low-level paraplegia demonstrate peak fat oxidation levels at around $55 \%$ of $\mathrm{VO}_{2 \text { peak }}($ Knechtle et al. 
2003). During prolonged voluntary exercise (40-80 minutes at $\left.60-65 \% \mathrm{VO}_{2 \text { peak }}\right)$, those with lowlevel paraplegia also showed increasing serum free fatty acids and a decreasing respiratory exchange ratio over time, whereas high-level paraplegia (T3-T5) had lower circulating norepinephrine, epinephrine and free fatty acids (Skrinar et al. 1982, Gass and Camp 1987, Hooker and Wells 1990, Stallknecht et al. 2001). The progressive increase in lipid metabolism in low-paraplegia that is not seen in those with high-paraplegia demonstrates the important role that increasing spinal sympathetic input plays in endurance-based exercise (Thompson et al. 2012).

The increasing use of serum free fatty acids with prolonged exercise appears to require at least partial sympathetic innervation, since those with tetraplegia show no change in lipid metabolism over 90 minutes of exercise (Campbell et al. 2004). This lack of increase in fat oxidation over time may be due to athletes with tetraplegia needing to function at higher relative peak aerobic capacity $\left(>65 \%\right.$ peak $\mathrm{VO}_{2}$ ) compared to paraplegia-level injury (Eriksson et al. 1988, Bhambhani et al. 1994), or due to absent sympathetic neural mechanisms for increasing fat lipolysis either via catecholamine release from the adrenal medulla or via direct sympathetic neural activation of adipose tissue. Regardless of the mechanism, training under these free fatty acid-deprived conditions alters the training responses in skeletal muscle compared to paraplegialevel SCI. In particular, anterior deltoid muscle fibre histochemistry reveals a preponderance of Type I oxidative fibres ( $>80 \%)$ in trained tetraplegia-level athletes compared to trained paraplegia-level athletes (55\%). Paraplegia-level athletes also showed a preferential increase in Type IIa fibres (32\%) compared to trained tetraplegia-level athletes (13\%). Blood vessel capillarization per millimetre was similar between groups (Schantz et al. 1997). 


\section{Recognition of the sympathetic contributions to performance: elite athletes with retained autonomic function show improved performance compared to 'autonomically- complete' competitors in tetraplegia}

Spinal cord injury is very rarely, if ever, anatomically 'complete' and there are often spared descending or ascending fibres that traverse the injury site, or undamaged neurons within the spinal grey matter that may help mediate descending commands from higher centres (Cowley et al. 2010, Harkema et al. 2011). Historically, the concept of complete injury related only to sensory and motor systems. Specific assessment of retained autonomic function, either by response to orthostatic challenge (Claydon and Krassioukov 2006), sweating in response to heat (Fealey 2013), or upper limit of peak HR response were not performed. However, observations that some with motor complete tetraplegia have higher than expected HR values [e.g. (Knechtle et al. 2003)], peak $\mathrm{VO}_{2}$ [e.g. $31.1 \mathrm{ml} \cdot \mathrm{kg}^{-1} \cdot \mathrm{min}^{-1}$ in (Paulson et al. 2013)], or the ability to sweat in response to heat [e.g. (Gass et al. 2002)], suggested the presence of retained autonomic function, in the absence of spared sensory or motor pathways. Thus, standards to document remaining autonomic function after SCI were introduced (Alexander et al. 2009). The contribution of preserved sympathetic function was demonstrated by the significantly faster times of those with autonomically-incomplete tetraplegia at the 2013 Paracycling World championships [ 500 s, $\sim 20 \%$ in the $17.3 \mathrm{~km}$ timed trial (West et al. 2014)]. 'Boosting', the practice of purposely inducing autonomic dysreflexia, a hyper-reflexive sympathetic discharge response evoked by a variety of stimuli (e.g. bladder distension, skin pinching), has been used by athletes with tetraplegia to improve race-time performance and circulating catecholamine levels [Table 1; 
(Wheeler et al. 1994, Schmid et al. 2001)]. These findings highlight the key role of sympathetic neural support during exercise in those with tetraplegia.

\section{Part I Summary: sympathetic function and exercise capabilities based on injury level}

In summary, the sympathetic autonomic system plays several critical roles in supporting exercise. In terms of quantity of muscle under voluntary control, there is very little difference between a person with a low cervical injury (e.g. C8) and a high thoracic level injury (e.g. T4), yet exercise capability differs greatly. After complete cervical SCI, descending arm motor, respiratory and cranial parasympathetic command pathways are the main means of producing and supporting movement. In addition, there is no central neural means to increase cardiovascular, thermoregulatory and energy substrate metabolism support in endurance-based rhythmic exercise. Acute and training-based responses are therefore dependent upon circulating hormonal and local peripheral mechanisms and performance is therefore severely limited. For those injured below $\sim \mathrm{T} 4 / \mathrm{T} 5$, the sympathetic input to increase HR and contractility is present. Partial thermoregulatory responses will be present for cooling in hot environments, as vasomotor, sweating and cutaneous vasodilation will be possible for the dermatomes above the neurological level of injury. For those with injury level that is below (caudal to) the innervation of the adrenal glands ( T6 - T10), normal exercise-induced release of circulating catecholamines is present. With injury below the sympathetic innervation of the splanchnic region (below $\sim \mathrm{T} 12$ ), despite lacking sympathetic regulation in the legs, there is a relatively normal capability for exercise. In essence then, the spinal sympathetic neural components that support endurancebased arm exercise arise from spinal segments located at lower (caudal) spinal levels than those that contain the neurons and motoneurons generating rhythmic movements. 


\section{A conceptual framework for the rostroventral medulla as the final supraspinal descending 'exercise integration centre'}

This section examines the rationale that the rostroventral medualla (RVM) is the key integration centre coordinating the production of locomotion with the sympathetic homeostatic and metabolic resources needed for endurance-based, rhythmic motor activity. It also provides the rationale for the concept of an ascending spinal neural drive from the lower to the upper limbs that may serve to integrate locomotor rhythm production and sympathetic support within the spinal cord during exercise. These interrelationships are shown schematically in Figure 2.

\section{A. The production of rhythmic locomotor activity by the brainstem-spinal cord}

Although higher centres such as the cortex, basal ganglia and cerebellum are needed for the full expression of movement, these centres act on a rhythm generating 'kernel' that exists within the brainstem-spinal network. Since first being described in the late 1960's, the mesencephalic locomotor region (MLR; see Figure 3) has primarily been used as a tool to study the neural basis of locomotion. Descending locomotor command signals originating in the MLR induce stepping, and at higher intensities of stimulation activate trot and ultimately gallop in decerebrate cats (Shik et al. 1969, Shik and Orlovsky 1976, Schmidt and Jordan 2000, Jordan et al. 2008). Under these experimental conditions, the animals' muscles are typically paralyzed by curare; the motor activity is recorded from peripheral leg nerves, and is termed 'fictive locomotion' since there is no movement of the limbs. However, normally, locomotor activity requires coordinated activation of neural circuitry to support these rhythmic movements, in terms of descending sympathetic drive for cardiovascular, thermoregulatory and energy substrate mobilization 
responses. Rhythmic activities such as running and cycling could only be maintained at very low intensities or for very brief episodes without the ongoing neural integration between the descending locomotor signal and the simultaneous activation of the appropriate sympathetic support systems. This review proposes that the rostroventral medulla (RVM) is the integration centre that coordinates rhythmic lower limb movements with the needed and appropriate sympathetic support to maintain these rhythmic movements.

The final relay site in the brainstem activated by MLR stimulation is the parapyramidal region (PPR) within the RVM. Figure 3 outlines the locomotor command pathway taken within the brainstem and spinal cord, and identifies key neurotransmitters in cell bodies of the parapyramidal region of the medulla [Figure 3: green hatching; CPG (central pattern generator); see full figure in supplemental materials], including serotonin and the excitatory amino acids glutamate and aspartate. The serotonergic pathway activated by PPR stimulation is thought to be the lateral paragigantocellular nucleus pathway projecting to the spinal cord (Jones and Light 1992, Liu and Jordan 2005). Descending unmyelinated serotonin fibres and collaterals provide input to interneurons and motoneurons at multiple spinal levels and are activated by MLR stimulation. These neurons release serotonin and mediate 'state-dependent' changes that facilitate rhythmic motor activity, such as voltage threshold hyperpolarization (Gilmore and Fedirchuk 2004), plateau potentials (Hounsgaard and Kiehn 1989), persistent inward currents (Brownstone et al. 1994, Murray et al. 2010), and may be involved in presynaptic inhibition of hindlimb afferents during rhythmic hindlimb activity (Sirois et al. 2013). These neuromodulatory changes support rhythm production mediated by fast neurotransmitters acting in the PPR (Figure 3), and additionally likely involve multiple neurotransmitter types (Heckmann et al. 2005, Power 
et al. 2010). This region of the medulla is also a key site providing sympathetic input to cardiovascular, thermoregulatory and adipose tissue, as described below (Section II B).

In terms of the spinal pathways and regions important in generating rhythmic motor activity, investigations using the in vitro neonatal rat brainstem-spinal cord preparation reveal a distributed system of neurons capable of generating and coordinating left-right and flexorextensor hindlimb rhythmic discharge (Cowley and Schmidt 1994, Cowley and Schmidt 1995, Kiehn and Kjaerulff 1996, Gabbay et al. 2002). Caudal thoracic and rostral lumbar segments are particularly rhythmogenic (Cazalets et al. 1995, Kjaerulff and Kiehn 1996, Cowley and Schmidt 1997, Kremer and Lev-Tov 1997, Magnuson and Trinder 1997), and contain critical commissural fibres mediating left-right coordination for the entire hindlimb (Cowley et al. 2009). Serotonin or noradrenaline, when combined with NMDA receptor activation, induce rhythmic patterns of flexor-extensor discharge most consistent with overground locomotion (Cowley and Schmidt 1994, Kiehn and Kjaerulff 1996). Interneurons labelled with activity-dependent markers are diffusely distributed throughout the lower thoracic and upper lumbar spinal cord segments, located mainly in intermediate and ventral grey matter (Kjaerulff and Kiehn 1996, Cina and Hochman 2000). Thus the most rhythmogenic and left-right coordinating spinal elements are localized in upper lumbar and lower thoracic spinal regions, a region rich in spinal sympathetic preganglionic neurons innervating adipose, vasomotor, adrenal and other key tissues needed to support rhythmic movement.

In addition, data from in vitro research supports the idea that there is an ascending hindlimb to forelimb drive in locomotor rhythm generation (Figure 2). First, although the cervical region can 
generate rhythmic activity, there appears to be a caudal to rostral gradient of activation (Ballion et al. 2001). Second, the lumbar and thoracic rhythmogenic circuitry can entrain or drive rhythmic activity in forelimb regions (Juvin et al. 2005, Juvin et al. 2012). In contrast, the ability of the cervical enlargement to drive the lumbar enlargement is present, but less powerful (Cowley et al. 2008, Juvin et al. 2012). Third, electrical stimulation of the ventrolateral funiculus, at low cervical levels, will produce rhythmic hindlimb activity (Magnuson and Trinder 1997), and this activation is thought to be due to retrograde activation of a bilateral ascending propriospinal system (Reed et al. 2006). Additionally, this ascending bilateral system crosses the midline below T9 (Reed et al. 2006), a region rich in pre-ganglionic intermediolateralis (IML) neurons innervating adrenal and other sympathetic tissue [e.g. (Strack et al. 1988)].

For most omnivorous mammals, including humans, the arms or forelimbs engage in a wide variety of relatively short duration movements such as grooming, feeding or grasping. The legs or the hindlimbs have a more limited repertoire, and subserve a more dedicated purpose: moving us from place to place. From a motor coordination standpoint, there is strong evidence for bidirectional motor integration between the upper and lower limbs [reviewed in (Zehr et al. 2016)]. From an energy needs and homeostasis standpoint, a 'bottom-up' form of activation makes sense: it is only when the legs (or hindlimbs) are engaged in prolonged rhythm production that an integrated sympathetic drive is needed, and therefore activated in parallel with the descending locomotor command signal from the brainstem reticular formation. Interestingly, vascular research in humans supports this concept of a 'bottom-up' integration between the sympathetic regulation of blood flow and the generation of endurance-based rhythmic locomotor activity. For example, brachial and forearm shear rate is increased (and therefore nitric oxide release and local 
vasodilation and blood flow) during leg cycling and walking, but not during repeated leg kicking or isotonic hand-grip (Green et al. 2005, Thijssen et al. 2009). Thus, metabolic support appears to be present only for sustained rhythmic locomotor movements. Further, although leg cycling increases shear rate in the brachial arteries, arm cycling does not increase femoral artery dilation and blood flow (Thijssen et al. 2009). These findings support the concept of a strong ascending sympathetic drive during rhythmic locomotor activity in the legs compared to a reduced or absent descending sympathetic drive during rhythmic activity in the arms.

\section{B. The parapyramidal region of the rostral ventrolateral medulla is a key site for cardiovascular, thermoregulatory and adipose tissue activation and integration}

\section{B i. Cardiovascular function}

The rostral ventrolateral medulla (RVLM) has been well described as a key cardiovascularregulating brain region [e.g. pressor response; (Loewy and Spyer 1990, Schreihofer and Sved 2011)]. The RVLM mediates tonic sympathetic drive for basal vasomotor tone ( $\sim$ Bregma 12.24), and stimulation of this region increases HR and mean arterial pressure (Schreihofer and Sved 2011). Similar to the parapyramidal locomotor region, the RVLM contains glutamate- and catecholamine-containing neurons, as well as myelinated and unmyelinated descending fibres (Schreihofer and Sved 2011). Proposed functions for these sympathetic descending neurons parallel those demonstrated for locomotor-related neurons in the parapyramidal region (Brownstone and Chopek 2018). These include amplifying excitatory inputs, or setting the level of excitability in sympathetic preganglionic neurons in order to modify responses to other inputs (Schreihofer and Sved 2011). 
Chong and Bedford (1997) demonstrated the parallel activation and inter-relationships between blood pressure, HR and locomotion speed with increasing intensity of tonic MLR stimulation. Specifically, animals increased walking speed with increasing stimulation of the MLR, and at higher current intensities, the pattern converted to a fast gallop, with some rats running beyond $100 \mathrm{~m} / \mathrm{min}$. Mean arterial pressure and HR were simultaneously increased. Thus, electrical stimulation of the single brainstem site (MLR) induced an integrated response that included the increased frequency of flexion and extension and the concomitant increase in activation of the sympathetic nervous system to increase blood pressure and HR. After applying curare, stimulation of the MLR still increased blood pressure and activated hindlimb nerves (fictive locomotion), but without an increase in HR, and this was attributed to the absence of active input from leg afferents (Chong and Bedford 1997).

\section{B ii. Lipolysis}

Retrograde labelling and electrophysiological studies demonstrate direct sympathetic neural innervation of white adipose tissue [reviewed in (Bartness et al. 2014)]. For example, after bilateral adrenal medullas are removed, lipolysis can be elicited by electrical stimulation in the hypothalamus; and can be blocked by the beta-adrenergic antagonist propranolol (Takahashi and Shimazu 1981). In humans, ten minutes of intraneural stimulation of sympathetic nerves innervating leg subcutaneous adipose tissue increased interstitial free fatty acids, and did so without increasing circulating free fatty acids, norepinephrine or epinephrine (Dodt et al. 1999). 
Retrograde labelling (using pseudo-rabies virus (PRV) conjugated to fluorescent dyes) demonstrates the direct neural communication between sympathetic neurons in the RVM and white adipose tissue. When injected into white adipose tissue, PRV (and fluorescent dye label) is taken up by nerve endings and is retrogradely transported to neuron cell bodies and then dendrites. With longer incubation periods, virus is taken up by higher order neurons that communicate with these last-order neurons. In the example shown in Figure 4A, injections of fluorescent PRV into abdominal (retroperitoneal, green) or subcutaneous inguinal leg (red) fat labelled cells within the IML of the T8 to T10 spinal cord (Figure 4A1, 4A2) as well as in the parapyramidal region of the medulla (Bregma - 10.52; Figure 4A3, 4A4). Neurons in the spinal cord and RVM showing innervation of both adipose tissues appear yellow [arrows, (Adler et al. 2012)]. These dual-labelled neurons in the RVM and spinal cord could therefore provide a synaptic signal to both fat depots simultaneously during rhythmic locomotor movements. Thus, the sympathetic brainstem-spinal innervation of white adipose tissue provides an additional activation mechanism that could be elicited in parallel with a descending locomotor command signal from the RVM.

\section{B iii. Retrograde labelling from adrenal, thermoregulatory, adipose and muscle tissues reveals similar patterns of neuron distribution within the spinal cord and RVM}

Although carried out in separate studies, injection of PRV into multiple different sympathetic tissues elicits a similar pattern of neuron labelling within the spinal cord and brainstem. In particular, injections of PRV into either the adrenal medulla, thermoregulatory-related cutaneous vasodilator nerves or adipose tissue all result in labelling of sympathetic pre-ganglionic neurons within the intermediolateral nucleus of the thoracic spinal cord as well as cell bodies within the 
parapyramidal region of the rostroventral medulla [e.g. Figure 4A and (Strack et al. 1988, Bamshad et al. 1998, Smith et al. 1998, Bamshad et al. 1999, Oldfield et al. 2002, Adler et al. 2012)]. Additional neurons were labelled around the central canal (lamina X) and in lamina VII (Strack et al. 1988). These spinal anatomical findings correlate with the distributed and redundant organization of the propriospinal system that mediates and coordinates locomotion, as demonstrated by electrophysiological and labelling experiments in vitro and in vivo in rat (Magnuson and Trinder 1997, Cina and Hochman 2000, Reed et al. 2006, Cowley et al. 2009). Further, when a distinct recombinant of PRV was injected into the gastrocnemius muscle and another (conjugated to a different fluorescent dye) was injected into the adrenal gland, neurons containing both labels were observed within the brainstem. The highest numbers of co-labelled neurons were seen in the rostral ventromedial medulla, lateral to the raphe magnus at the level of the $7^{\text {th }}$ cranial nerve (Kerman et al. 2003). These results indicate that these dual-labelled neurons project to both the pre-ganglionic neurons of the adrenal medulla, and to interneurons that ultimately project to gastrocnemius motoneurons. Thus, the same neuron in the RVM may simultaneously activate the adrenal gland and interneurons responsible for activation of the gastrocnemius muscle.

Chemogenetic activation of sub set of serotonin containing cells within the parapyramidal region activates locomotion and simultaneously increases mean arterial pressure in genetically modified decerebrate rat

Evidence from genetically modified rats supports the concept of sympathetic-locomotor integration occurring in cells within the rostroventrolateral medulla (RVLM; Figure 4B). In particular, locomotor activity and increased mean arterial pressure occur in response to injection 
of a designer-drug that activates genetically modified serotonin-containing neurons within the RVLM (red). Figure 4B1 shows the schematic of injection site and section of the brainstem shown in B3-B4 (Bregma - 11.5). Figures 4B3 and 4B4 show all serotonin containing neurons (green) and the sub-set of serotonergic neurons that have been genetically modified (containing the reporter mCherry, red). Note that the drug injection first evoked a rise in mean arterial pressure (Figure 4B2, top trace), and then locomotor activity (bottom 4 traces in Figure 4B2). Note also that the rise in mean arterial pressure outlasted the bout of rhythmic motor activity in left and right tibial and common peroneal nerves (Armstrong et al. 2017). It is likely that a similar integration occurs for linking these responses in humans as well: simply the attempt to move is associated with increases in blood pressure and HR in humans temporarily paralyzed by neuromuscular blockade (Gandevia et al. 1993). Finally, comparing Figure 4A to 4B demonstrates the overlapping distribution of adipose-related sympathetic neurons (4A) with the genetically modified locomotor-related neurons (4B) in the RVM.

The concept of an integration centre for the coordinated activation of motor and autonomic neural circuits whose function is to provide metabolic support for the ongoing production of rhythmic movements

Taken together, the findings summarized in section II support the conceptual framework presented in Figure 2. The schematic is intended to illustrate the interrelationships and feedback interactions between brainstem-spinal sympathetic autonomic support neurons; locomotor neurons mediating the descending command signal; and the propriospinal network producing locomotor rhythms. Peripheral afferent feedback is not shown. Within the proposed conceptual framework, activation of the MLR results in excitation of locomotor neurons in the PPR and 
simultaneous activation of the appropriate sympathetic cardiovascular, thermoregulatory and energy substrate support. This region of the RVM would represent the final descending supraspinal integration site. It is conceivable that 'failure' within any of the needed sympathetic spinal autonomic support systems could provide inhibitory feedback or reduced excitatory input to locomotor command neurons within the PPR. This failure to activate descending locomotor command neurons would then fail to activate the propriospinal neurons that produce rhythmic motor activity. Whether this reduction in central locomotor command involves serotonin spillover mechanisms as described previously during prolonged stimulation of the raphe-spinal pathway in turtle motoneurons is unknown (Cotel et al. 2013).

\section{Implications after spinal cord injury and future research targeting impaired sympathetic function during rhythmic locomotor activity}

It is likely that multiple components of impaired sympathetic function contribute to the impaired exercise response after SCI. Trained endurance athletes with tetraplegia report 'motor fatigue' and the need to stop producing rhythmic movement for a variety of reasons, including being 'too hot' or feelings of increasing 'arm burn.' Once these symptoms are alleviated, by cold water application, or a few seconds of rest, rhythmic movement can continue. The conceptual framework presented here can account for these anecdotal observations. In addition, this framework could inform future clinical exercise research strategies targeting specific sympathetic functions to improve performance after cervical SCI. For example, caffeine increases mobilization of free fatty acids at rest, but only in those with tetraplegia (GrahamPaulson et al. 2017). Since adenosine directly inhibits lipolysis and caffeine is an adenosine receptor antagonist at all four subtypes of the adenosine receptor (Bartness et al. 2014), it would 
be of interest to test if those with an absent sympathetic response would benefit from caffeine supplementation during prolonged exercise performance.

This unifying framework also provides a basis for future animal-based research investigating the inter-relationships between locomotor rhythm production and sympathetic activation within the brainstem and spinal cord. For example, can neurotransmitters that elicit rhythmic motor activity from a single spinal segmental level (Cowley and Schmidt 1997) also activate lipolysis in white adipose tissue from a single spinal segment? What spinal neural mechanisms elicit lipolysis during locomotor activity elicited by activation of locomotor command neurons within the RVM? What parameters might activate ascending spinal sympathetic neural drive and would such an activation improve motor rhythm production?

\section{Overall view}

The historical focus after SCI has been the loss of sensation and voluntary movement. However, it is really the disordered autonomic nervous system that leads to the greatest impairments after injury, both for maintaining rhythmic movements in exercise, and for other important bodily functions. For a review of non-exercise related autonomic consequences of SCI (e.g. altered bladder, bowel, sexual function), the reader is referred elsewhere (Hou and Rabchevsky 2014). In terms of the acute exercise response, this review demonstrates that the spinal sympathetic autonomic nervous system is critical for maintaining ongoing rhythmic movements, and that limitations to prolonged endurance performance in cervical level injury are due to a combination of blunted cardiovascular, metabolic and thermoregulatory responses. This review also provides a conceptual framework linking the generation of rhythmic motor activity with the spinal 
sympathetic autonomic support systems. This integration is needed to maintain thermoregulation and to provide and remove metabolic substrates in active tissues during prolonged rhythmic activity. Hopefully this review highlights the need to consider the integration between the sympathetic and locomotor brainstem-spinal systems, and how dysfunction of this integration affects a person's exercise response after spinal cord injury.

\section{Acknowledgements}

The author thanks Chris MacDonnell, Katinka Stecina, Larry Jordan, Brent Fedirchuk, Brian Schmidt, Phil Gardiner, Jessie Shea and Kevin Power for the many energetic and invaluable discussions regarding the integration between brainstem-propriospinal locomotor and sympathetic control systems. The author acknowledges the support of the Natural Sciences and Engineering Research Council of Canada (NSERC), [funding reference number RGPIN-201504810], the Manitoba Spinal Cord Injury Research Committee (Canadian Paraplegic Association (Manitoba) Inc., Rick Hansen Institute and Government of Manitoba), and a Will-to-Win Professorship.

The author has no conflicts of interest to declare. 


\section{References}

Adler, E. S., Hollis, J. H., Clarke, I. J., Grattan, D. R. and Oldfield, B. J. 2012. Neurochemical characterization and sexual dimorphism of projections from the brain to abdominal and subcutaneous white adipose tissue in the rat. J. Neurosci. 32(45): 15913-15921.

PMID:23136429.

Alexander, M. S., Biering-Sorensen, F., Bodner, D., Brackett, N. L., Cardenas, D., Charlifue, S., et al. 2009. International standards to document remaining autonomic function after spinal cord injury. Spinal Cord, 47(1): 36-43. PMID:18957962.

Altus, P., Hickman, J. W. and Nord, H. J. 1985. Accidental hypothermia in a healthy quadriplegic patient. Neurology, 35(3): 427-428. PMID:3974905.

Armstrong, K. E., Nazzal, M., Chen, X., Stecina, K. and Jordan, L. M. 2017. Chemogenic activation of parapyramidal brainstem neurons to evaluate motor consequences. Society for Neuroscience Abstracts, Washington DC, USA., Society for Neuroscience. 65.15. Available from http://www.abstractsonline.com/pp8/\#!/4376/presentation/4276 [accessed 9 May 2018]

Ballion, B., Morin, D. and Viala, D. 2001. Forelimb locomotor generators and quadrupedal locomotion in the neonatal rat. Eur J. Neurosci. 14(10): 1727-1738. PMID:11860467. Bamshad, M., Aoki, V. T., Adkison, M. G., Warren, W. S. and Bartness, T. J. 1998. Central nervous system origins of the sympathetic nervous system outflow to white adipose tissue. Am. J. Physiol. 275(1 Pt 2): R291-299. PMID:9688991.

Bamshad, M., Song, C. K. and Bartness, T. J. 1999. CNS origins of the sympathetic nervous system outflow to brown adipose tissue. Am. J. Physiol. 276(6 Pt 2): R1569-1578.

PMID:10362733. 
Bartness, T. J., Liu, Y., Shrestha, Y. B. and Ryu, V. 2014. Neural innervation of white adipose tissue and the control of lipolysis. Front. Neuroendocrinol. 35(4): 473-493.

PMID:24736043.

Bartness, T. J., Shrestha, Y. B., Vaughan, C. H., Schwartz, G. J. and Song, C. K. 2010. Sensory and sympathetic nervous system control of white adipose tissue lipolysis. Mol. Cell Endocrinol. 318(1-2): 34-43. PMID:19747957.

Bhambhani, Y. 2002. Physiology of wheelchair racing in athletes with spinal cord injury. Sports. Med. 32(1): 23-51. PMID:11772160.

Bhambhani, Y. N., Holland, L. J., Eriksson, P. and Steadward, R. D. 1994. Physiological responses during wheelchair racing in quadriplegics and paraplegics. Paraplegia, 32(4): 253-260. PMID:8022635.

Brownstone, R. M. and Chopek, J. W. 2018. Reticulospinal Systems for Tuning Motor Commands. Front. Neural Circuits. 12: 30. PMID:29720934.

Brownstone, R. M., Gossard, J. P. and Hultborn, H. 1994. Voltage-dependent excitation of motoneurones from spinal locomotor centres in the cat. Exp. Brain Res. 102(1): 34-44. PMID:7895797.

Campbell, I. G., Williams, C. and Lakomy, H. K. 2004. Physiological and metabolic responses of wheelchair athletes in different racing classes to prolonged exercise. J. Sports Sci. 22(5): 449-456. PMID:15160598.

Cazalets, J. R., Borde, M. and Clarac, F. 1995. Localization and organization of the central pattern generator for hindlimb locomotion in newborn rat. J. Neurosci. 15(7): 4943-4951. PMID:7623124. 
Chong, R. K. and Bedford, T. G. 1997. Heart rate, blood pressure, and running speed responses to mesencephalic locomotor region stimulation in anesthetized rats. Pflugers Archives. 434(3): 280-284. PMID:9178627.

Cina, C. and Hochman, S. 2000. Diffuse distribution of sulforhodamine-labeled neurons during serotonin-evoked locomotion in the neonatal rat thoracolumbar spinal cord. J. Comp. Neurol. 423(4): 590-602. PMID:10880990.

Claydon, V. E. and Krassioukov, A. V. 2006. Orthostatic hypotension and autonomic pathways after spinal cord injury. J. Neurotrauma. 23(12): 1713-1725. PMID:17184183. Cotel, F., Exley, R., Cragg, S. J. and Perrier, J. F. 2013. Serotonin spillover onto the axon initial segment of motoneurons induces central fatigue by inhibiting action potential initiation. Proc. Natl. Acad. Sci. U. S. A. 110(12): 4774-4779. PMID:23487756.

Cowley, K. C. and Schmidt, B. J. 1994. A comparison of motor patterns induced by N-methylD-aspartate, acetylcholine and serotonin in the in vitro neonatal rat spinal cord. Neurosci. Lett. 171: 147-150. PMID:8084477.

Cowley, K. C. and Schmidt, B. J. 1995. Effects of inhibitory amino acid antagonists on reciprocal inhibitory interactions during rhythmic motor activity in the in vitro neonatal rat spinal cord. J. Neurophysiol. 74(3): 1109-1117. PMID:7500136.

Cowley, K. C. and Schmidt, B. J. 1997. Regional distribution of the locomotor patterngenerating network in the neonatal rat spinal cord. J. Neurophysiol. 77: 247-259. PMID:9120567.

Cowley, K. C., Zaporozhets, E., Joundi, R. A. and Schmidt, B. J. 2009. Contribution of commissural projections to bulbospinal activation of locomotion in the in vitro neonatal rat spinal cord. J. Neurophysiol. 101(3): 1171-1178. PMID:19118107. 
Cowley, K. C., Zaporozhets, E. and Schmidt, B. J. 2008. Propriospinal neurons are sufficient for bulbospinal transmission of the locomotor command signal in the neonatal rat spinal cord. J. Physiol. 586(6): 1623-1635. PMID:18238807.

Cowley, K. C., Zaporozhets, E. and Schmidt, B. J. 2010. Propriospinal transmission of the locomotor command signal in the neonatal rat. Ann. N. Y. Acad. Sci. 1198: 42-53. PMID:20536919.

Dela, F., Mohr, T., Jensen, C. M., Haahr, H. L., Secher, N. H., Biering-Sorensen, F., et al. 2003. Cardiovascular control during exercise: insights from spinal cord-injured humans. Circulation, 107(16): 2127-2133. PMID:12695298.

Dodt, C., Lonnroth, P., Fehm, H. L. and Elam, M. 1999. Intraneural stimulation elicits an increase in subcutaneous interstitial glycerol levels in humans. J. Physiol. 521 Pt 2: 545552. PMID:10581323.

Eriksson, P., Lofstrom, L. and Ekblom, B. 1988. Aerobic power during maximal exercise in untrained and well-trained persons with quadriplegia and paraplegia. Scand. J. Rehabil. Med. 20(4): 141-147. PMID:3232045.

Fealey, R. D. 2013. Interoception and autonomic nervous system reflexes thermoregulation. Handb. Clin. Neurol. 117: 79-88. PMID:24095117.

Gabbay, H., Delvolve, I. and Lev-Tov, A. 2002. Pattern generation in caudal-lumbar and sacrococcygeal segments of the neonatal rat spinal cord. J. Neurophysiol. 88(2): 732-739. PMID:12163525.

Gandevia, S. C., Killian, K., McKenzie, D. K., Crawford, M., Allen, G. M., Gorman, R. B., et al. 1993. Respiratory sensations, cardiovascular control, kinaesthesia and transcranial stimulation during paralysis in humans. J. Physiol. 470: 85-107. PMID:8308755. 
Gass, E. M., Gass, G. C. and Pitetti, K. 2002. Thermoregulatory responses to exercise and warm water immersion in physically trained men with tetraplegia. Spinal Cord. 40(9): 474480. PMID:12185609.

Gass, G. C. and Camp, E. M. 1987. Effects of prolonged exercise in highly trained traumatic paraplegic men. J. Appl. Physiol. (1985). 63(5): 1846-1852. PMID:3693218.

Gilmore, J. and Fedirchuk, B. 2004. The excitability of lumbar motoneurones in the neonatal rat is increased by a hyperpolarization of their voltage threshold for activation by descending serotonergic fibres. J. Physiol. 558(Pt 1): 213-224. PMID:15121804. Graham-Paulson, T. S., Paulson, T. A., Perret, C., Tolfrey, K., Cordery, P. and Goosey-Tolfrey, V. L. 2017. Spinal Cord Injury Level Influences Acute Plasma Caffeine Responses. Med. Sci. Sports Exerc. 49(2): 363-370. PMID:27669443.

Green, D. J., Bilsborough, W., Naylor, L. H., Reed, C., Wright, J., O'Driscoll, G., et al. 2005. Comparison of forearm blood flow responses to incremental handgrip and cycle ergometer exercise: relative contribution of nitric oxide. J. Physiol. 562(Pt 2): 617-628.

PMID:15513940.

Green, D. J., Dawson, E. A., Groenewoud, H. M. M., Jones, H. and Thijssen, D. H. J. 2014. Is Flow-Mediated Dilation Nitric Oxide Mediated? A Meta-Analysis. Hypertension, 63(2): 376382. PMID:24277765.

Griggs, K. E., Price, M. J. and Goosey-Tolfrey, V. L. 2015. Cooling athletes with a spinal cord injury. Sports Med. 45(1): 9-21. PMID:25119157.

Guttmann, L., Silver, J. and Wyndham, C. H. 1958. Thermoregulation in spinal man. J. Physiol. 142(3): 406-419. PMID:13576444. 
Handrakis, J. P., Rosado-Rivera, D., Singh, K., Swonger, K., Azarelo, F., Lombard, A. T., et al. 2017. Self-reported effects of cold temperature exposure in persons with tetraplegia. J. Spinal Cord Med. 40(4): 389-395. PMID:27077570.

Harkema, S., Gerasimenko, Y., Hodes, J., Burdick, J., Angeli, C., Chen, Y., et al. 2011. Effect of epidural stimulation of the lumbosacral spinal cord on voluntary movement, standing, and assisted stepping after motor complete paraplegia: a case study. Lancet, 377(9781): 19381947. PMID:21601270.

Heckmann, C. J., Gorassini, M. A. and Bennett, D. J. 2005. Persistent inward currents in motoneuron dendrites: implications for motor output. Muscle Nerve, 31(2): 135-156. PMID:15736297.

Hooker, S. P. and Wells, C. L. 1990. Physiologic responses of elite paraplegic road racers to prolonged exercise. J. Am. Paraplegia Soc. 13(4): 72-77. PMID:2258732.

Hopman, M. T., Oeseburg, B. and Binkhorst, R. A. 1993. Cardiovascular responses in persons with paraplegia to prolonged arm exercise and thermal stress. Med. Sci. Sports Exerc. 25(5): 577-583. PMID:8492685.

Hou, S. and Rabchevsky, A. G. 2014. Autonomic consequences of spinal cord injury. Compr. Physiol. 4(4): 1419-1453. PMID:25428850.

Hounsgaard, J. and Kiehn, O. 1989. Serotonin-induced bistability of turtle motoneurones caused by a nifedipine-sensitive calcium plateau potential. J. Physiol. 414: 265-282. PMID:2607432.

Jones, S. L. and Light, A. R. 1992. Serotoninergic medullary raphespinal projection to the lumbar spinal cord in the rat: a retrograde immunohistochemical study. J. Comp. Neurol. 322(4): 599-610. PMID:1383285. 
Jordan, L. M., Liu, J., Hedlund, P. B., Akay, T. and Pearson, K. G. 2008. Descending command systems for the initiation of locomotion in mammals. Brain Res. Rev. 57(1): 183-191. PMID:17928060.

Juvin, L., Le Gal, J. P., Simmers, J. and Morin, D. 2012. Cervicolumbar coordination in mammalian quadrupedal locomotion: role of spinal thoracic circuitry and limb sensory inputs. J. Neurosci. 32(3): 953-965. PMID:22262893.

Juvin, L., Simmers, J. and Morin, D. 2005. Propriospinal circuitry underlying interlimb coordination in mammalian quadrupedal locomotion. J. Neurosci. 25(25): 6025-6035. PMID:15976092.

Kandel, E., Schwartz, J., H. and Jessell, T. M. 2000. Principles of Neural Science. McGraw-Hill, New York, NY.

Kerman, I. A., Enquist, L. W., Watson, S. J. and Yates, B. J. 2003. Brainstem substrates of sympatho-motor circuitry identified using trans-synaptic tracing with pseudorabies virus recombinants. J. Neurosci. 23(11): 4657-4666. PMID:12805305.

Khan, S., Plummer, M., Martinez-Arizala, A. and Banovac, K. 2007. Hypothermia in patients with chronic spinal cord injury. J. Spinal Cord Med. 30(1): 27-30. PMID:17385266.

Kiehn, O. and Kjaerulff, O. 1996. Spatiotemporal characteristics of 5-HT and dopamineinduced rhythmic hindlimb activity in the in vitro neonatal rat. J. Neurophysiol. 75(4): 1472-1482. PMID:8727391.

Kjaerulff, O. and Kiehn, O. 1996. Distribution of networks generating and coordinating locomotor activity in the neonatal rat spinal cord in vitro: A lesion study. J. Neurosci. 16(18): 5777-5794. PMID:8795632. 
Knechtle, B., Muller, G., Willmann, F., Eser, P. and Knecht, H. 2003. Comparison of fat oxidation in arm cranking in spinal cord-injured people versus ergometry in cyclists. Eur. J. Appl. Physiol. 90(5-6): 614-619. PMID:12923642.

Kooijman, M., Thijssen, D. H., de Groot, P. C., Bleeker, M. W., van Kuppevelt, H. J., Green, D. J., et al. 2008. Flow-mediated dilatation in the superficial femoral artery is nitric oxide mediated in humans. J. Physiol. 586(4): 1137-1145. PMID:18096601.

Kremer, E. and Lev-Tov, A. 1997. Localization of the spinal network associated with generation of hindlimb locomotion in the neonatal rat and organization of its transverse coupling system. J. Neurophysiol. 77(3): 1155-1170. PMID:9084588.

Liu, J. and Jordan, L. M. 2005. Stimulation of the parapyramidal region of the neonatal rat brain stem produces locomotor-like activity involving spinal 5-HT7 and 5-HT2A receptors. J. Neurophysiol. 94(2): 1392-1404. PMID:15872068.

Loewy, A. D. and Spyer, K. M. 1990. Central Regulation of Autonomic Functions. Oxford University Press, Toronto, Ontario.

Lovell, D., Shields, D., Beck, B., Cuneo, R. and McLellan, C. 2012. The aerobic performance of trained and untrained handcyclists with spinal cord injury. Eur. J. Appl. Physiol. 112(9): 3431-3437. PMID: 22278391.

Magnuson, D. S. and Trinder, T. C. 1997. Locomotor rhythm evoked by ventrolateral funiculus stimulation in the neonatal rat spinal cord in vitro. J. Neurophysiol. 77(1): 200206. PMID:9120561.

McArdle, W. D., Katch, F. I. and Katch, V. L. 2001. Exercise Physiology: Energy, Nutrition, and Human Performance, Lippincott Williams and Wilkins. Philadelphia, PA. 
Murray, K. C., Nakae, A., Stephens, M. J., Rank, M., D'Amico, J., Harvey, P. J., et al. 2010. Recovery of motoneuron and locomotor function after spinal cord injury depends on constitutive activity in 5-HT2C receptors. Nat. Med. 16(6): 694-700. PMID:20512126. Nathan, P. W. and Smith, M. C. 1986. The location of descending fibres to sympathetic neurons supplying the eye and sudomotor neurons supplying the head and neck. J Neurol. Neurosurg. Psychiatry. 49(2): 187-194. PMID:3950636.

Nathan, P. W. and Smith, M. C. 1987. The location of descending fibres to sympathetic preganglionic vasomotor and sudomotor neurons in man. J. Neurol. Neurosurg. Psychiatry. 50(10): 1253-1262. PMID:3681303.

Ogawa, T., Nakamura, T., Banno, M., Sasaki, Y., Umemoto, Y., Kouda, K., et al. 2014. Elevation of interleukin- 6 and attenuation of tumor necrosis factor-alpha during wheelchair half marathon in athletes with cervical spinal cord injuries. Spinal Cord, 52(8): 601-605. PMID: 24891006

Oldfield, B. J., Giles, M. E., Watson, A., Anderson, C., Colvill, L. M. and McKinley, M. J. 2002. The neurochemical characterisation of hypothalamic pathways projecting polysynaptically to brown adipose tissue in the rat. Neuroscience, 110(3): 515-526. PMID:11906790. Paulson, T. A., Bishop, N. C., Leicht, C. A. and Goosey-Tolfrey, V. L. 2013. Perceived exertion as a tool to self-regulate exercise in individuals with tetraplegia. Eur. J. Appl. Physiol. 113(1): 201-209. PMID:22644568.

Power, K. E., McCrea, D. A. and Fedirchuk, B. 2010. Intraspinally mediated state-dependent enhancement of motoneurone excitability during fictive scratch in the adult decerebrate cat. J. Physiol. 588(Pt 15): 2839-2857. PMID:20547677. 
Price, M. J. 2006. Thermoregulation during exercise in individuals with spinal cord injuries. Sports Med. 36(10): 863-879. PMID:17004849.

Price, M. J. and Campbell, I. G. 1999. Thermoregulatory responses of spinal cord injured and able-bodied athletes to prolonged upper body exercise and recovery. Spinal Cord, 37(11): 772-779. PMID:10578248.

Reed, W. R., Shum-Siu, A., Onifer, S. M. and Magnuson, D. S. 2006. Inter-enlargement pathways in the ventrolateral funiculus of the adult rat spinal cord. Neuroscience, 142(4): 1195-1207. PMID:16938403.

Romijn, J. A., Coyle, E. F., Sidossis, L. S., Gastaldelli, A., Horowitz, J. F., Endert, E., et al. 1993. Regulation of endogenous fat and carbohydrate metabolism in relation to exercise intensity and duration. Am. J. Physiol. 265(3 Pt 1): E380-391. PMID:8214047.

Sato, A. 1987. Neural mechanisms of somatic sensory regulation of catecholamine secretion from the adrenal gland. Adv. Biophys. 23: 39-80. PMID:3326403.

Schantz, P., Sjoberg, B., Widebeck, A. M. and Ekblom, B. 1997. Skeletal muscle of trained and untrained paraplegics and tetraplegics. Acta. Physiol. Scand. 161(1): 31-39. PMID:9381947. Schmid, A., Huonker, M., Barturen, J. M., Stahl, F., Schmidt-Trucksass, A., Konig, D., et al. 1998. Catecholamines, heart rate, and oxygen uptake during exercise in persons with spinal cord injury. J. Appl. Physiol. 85(2): 635-641. PMID:9688742.

Schmid, A., Schmidt-Trucksass, A., Huonker, M., Konig, D., Eisenbarth, I., Sauerwein, H., et al. 2001. Catecholamines response of high performance wheelchair athletes at rest and during exercise with autonomic dysreflexia. Int. J. Sports Med. 22(1): 2-7. PMID:11258636. 
Schmidt, B. J. and Jordan, L. M. 2000. The role of serotonin in reflex modulation and locomotor rhythm production in the mammalian spinal cord. Brain. Res. Bull. 53(5): 689710. PMID:11165804.

Schreihofer, A. M. and Sved, A. F. 2011. The ventrolateral medulla and sympathetic regulation of arterial pressure. In Central regulation of autonomic functions. Edited by I. Llewellyn-Smith and A. J. Verberne. Oxford University Press, New York. xv, 401 p. Shik, M. L. and Orlovsky, G. N. 1976. Neurophysiology of locomotor automatism. Physiological Reviews, 56(3): 465-501. PMID:778867.

Shik, M. L., Severin, F. V. and Orlovsky, G. N. 1969. Control of walking and running by means of electrical stimulation of the mesencephalon. Electroencephalogr Clin. Neurophysiol. 26(5): 549. PMID:4181500.

Simard, C., Noreau, L., Pare, G. and Pomerleau, P. 1993. [Maximal physiological response during exertion in quadriplegic subjects]. Can. J. Appl. Physiol. 18(2): 163-174. PMID:8513289.

Sirois, J., Frigon, A. and Gossard, J. P. 2013. Independent control of presynaptic inhibition by reticulospinal and sensory inputs at rest and during rhythmic activities in the cat. J. Neurosci. 33(18): 8055-8067. PMID:23637195.

Skrinar, G. S., Evans, W. J., Ornstein, L. J. and Brown, D. A. 1982. Glycogen utilization in wheelchair-dependent athletes. Int. J. Sports Med. 3(4): 215-219. PMID:7152768. Smith, J. E., Jansen, A. S., Gilbey, M. P. and Loewy, A. D. 1998. CNS cell groups projecting to sympathetic outflow of tail artery: neural circuits involved in heat loss in the rat. Brain Res. 786(1-2): 153-164. PMID:9554992. 
Stallknecht, B., Lorentsen, J., Enevoldsen, L. H., Bulow, J., Biering-Sorensen, F., Galbo, H., et al. 2001. Role of the sympathoadrenergic system in adipose tissue metabolism during exercise in humans. J. Physiol. 536(Pt 1): 283-294. PMID:11579176.

Strack, A. M., Sawyer, W. B., Marubio, L. M. and Loewy, A. D. 1988. Spinal origin of sympathetic preganglionic neurons in the rat. Brain Res. 455(1): 187-191. PMID:3416186. Takahashi, A. and Shimazu, T. 1981. Hypothalamic regulation of lipid metabolism in the rat: effect of hypothalamic stimulation on lipolysis. J. Auton. Nerv. Syst. 4(3): 195-205. PMID:7299038.

Thijssen, D. H., Dawson, E. A., Black, M. A., Hopman, M. T., Cable, N. T. and Green, D. J. 2009. Brachial artery blood flow responses to different modalities of lower limb exercise. Med. Sci. Sports Exerc. 41(5): 1072-1079. PMID:19461541.

Thijssen, D. H., Steendijk, S. and Hopman, M. T. 2009. Blood redistribution during exercise in subjects with spinal cord injury and controls. Med. Sci. Sports Exerc. 41(6): 1249-1254. Thomas, G. D. and Segal, S. S. 2004. Neural control of muscle blood flow during exercise. J. Appl. Physiol. (1985). 97(2): 731-738. PMID:15247201.

Thomas, G. D. and Victor, R. G. 1998. Nitric oxide mediates contraction-induced attenuation of sympathetic vasoconstriction in rat skeletal muscle. J. Physiol. (Lond). 506(3): 817-826. Thompson, D., Karpe, F., Lafontan, M. and Frayn, K. 2012. Physical activity and exercise in the regulation of human adipose tissue physiology. Physiol. Rev. 92(1): 157-191. PMID: 22298655.

Wade, O. L. and Bishop, J. M. 1962. The distribution of the cardiac output in normal subjects at rest. In Cardiac Output and Regional Blood Flow. Edited by O. L. Wade and J. M. Bishop. Blackwell Scientific Publications, Oxford. 86 - 94. 
West, C. R., Gee, C. M., Voss, C., Hubli, M., Currie, K. D., Schmid, J., et al. 2015. Cardiovascular control, autonomic function, and elite endurance performance in spinal cord injury. Scand. J. Med. Sci. Sports. 25(4): 476-485. PMID:25175825.

Wheeler, G., Cumming, D., Burnham, R., Maclean, I., Sloley, B. D., Bhambhani, Y., et al. 1994. Testosterone, cortisol and catecholamine responses to exercise stress and autonomic dysreflexia in elite quadriplegic athletes. Paraplegia, 32(5): 292-299, PMID:8058345. Zehr, E. P., Barss, T. S., Dragert, K., Frigon, A., Vasudevan, E. V., Haridas, C., et al. 2016. Neuromechanical interactions between the limbs during human locomotion: an evolutionary perspective with translation to rehabilitation. Exp. Brain Res. 234(11): 30593081. PMID:27421291. 
Table 1: Peak responses during a variety of rhythmic exercises reveal the deficits resulting from impaired sympathetic neural function at different levels of spinal cord injury. Abbreviations: Wheelchair ergometry (WCE), arm crank ergometry (ACE), functional electrical stimulation (FES). * Values were converted from $\mathrm{nM}$ to $\mathrm{ng} / \mathrm{ml}$ using molecular weight of $169 \mathrm{~g} /$ mole for norepinephrine to facilitate comparisons.

\begin{tabular}{|c|c|c|c|c|c|}
\hline Injury Level & $\begin{array}{l}\mathrm{HR}_{\text {peak }} \\
(\mathrm{bpm})\end{array}$ & $\begin{array}{c}\mathrm{VO}_{2 \text { peak }} \\
\left(\mathrm{ml} \cdot \mathrm{kg}^{-1} \cdot \mathrm{min}^{-1}\right)\end{array}$ & $\begin{array}{l}\mathrm{PO}_{\text {peak }} \\
\text { (Watts) }\end{array}$ & $\begin{array}{l}\mathrm{NE}_{\text {peak }} \\
(\mathrm{ng} / \mathrm{ml})\end{array}$ & Source \\
\hline $\begin{array}{l}\text { Tetraplegia } \\
\text { Paraplegia }\end{array}$ & $110-130$ & $\begin{array}{l}<20 \\
>30\end{array}$ & & & $\begin{array}{l}\text { (Bhambhani } \\
\text { 2002) }\end{array}$ \\
\hline $\begin{array}{c}\mathrm{T} 1-\mathrm{T} 6 \\
\mathrm{~T} 7-\mathrm{T} 9 \\
\mathrm{~T} 10-\mathrm{T} 12 \\
\text { Able-bodied }\end{array}$ & $\begin{array}{c}158+/-20 \\
199+/-13 \\
188+/-2 \\
177+/-7\end{array}$ & $\begin{array}{c}18.8+/-7.7 \\
26.9+/-7.8 \\
38.1+/-2.9 \\
35.1+/-13.8\end{array}$ & & & $\begin{array}{c}\mathrm{ACE} \\
\text { (Hopman et } \\
\text { al. 1993) }\end{array}$ \\
\hline $\begin{array}{c}\text { Tetraplegia } \\
\text { T1 - T4 } \\
\text { T5 - T10 } \\
<\text { T10 }\end{array}$ & $\begin{array}{l}110+/-17 \\
172+/-13 \\
182+/-19 \\
176+/-19\end{array}$ & & $\begin{array}{c}33+/-9 \\
67+/-27 \\
79+/-20 \\
72+/-32\end{array}$ & $\begin{array}{l}0.34+/-0.18 \\
0.91+/-0.48 \\
2.08+/-0.81 \\
1.52+/-0.86\end{array}$ & $\begin{array}{c}\text { WCE } \\
\text { (Schmid et al. } \\
1998)\end{array}$ \\
\hline $\begin{array}{c}\text { Tetraplegia, } \\
\text { un-boosted } \\
\text { Tetraplegia, } \\
\text { boosted }\end{array}$ & $\begin{array}{l}149+/-24 \\
161+/-23\end{array}$ & & $\begin{array}{l}72.5+/-37 \\
77.5+/-36\end{array}$ & $\begin{array}{l}0.67+/-0.46 \\
1.05+/-0.75\end{array}$ & $\begin{array}{c}\text { WCE } \\
\text { (Schmid et al. } \\
2001)\end{array}$ \\
\hline $\begin{array}{c}\text { Tetraplegia } \\
\text { T3 to T5 } \\
\text { Able-bodied }\end{array}$ & $\begin{array}{l}110+/-5 \\
154+/-7 \\
177+/-3\end{array}$ & & & $\begin{array}{l}0.26+/-0.06^{*} \\
0.74+/-0.25^{*} \\
2.16+/-0.33^{*}\end{array}$ & $\begin{array}{c}\text { FES Cycling } \\
\text { (Dela et al. } \\
\text { 2003) } \\
\text { Leg Cycling }\end{array}$ \\
\hline
\end{tabular}

Figure 1: The peripheral sympathetic and parasympathetic innervation of key tissues and organs involved in supporting exercise. Data is adapted from multiple sources: (Strack et al. 1988, Loewy and Spyer 1990, Bamshad et al. 1998, Bamshad et al. 1999, Kandel et al. 2000). For simplicity, and to reduce overlap, only the spinal segments containing the majority (>80\%) of pre-ganglionic SNS neurons innervating the adrenal medulla, celiac ganglion and aortico-renal ganglion are shown. 
Figure 2: Medullary spinal control centre for integrating sympathetic autonomic support to sustain locomotor rhythm production. Propriospinal component of figure is adapted from Cowley et al. 2008. WAT is white adipose tissue and BAT is brown, heat generating adipose tissue.

Figure 3: Stimulation of the MLR elicits rhythmic hindlimb flexion and extension via a relay in the parapyramidal region of the rostroventral medulla. Figure and legend modified, with permission, from Jordan et al., 2008. Full version is in supplemental materials (supplementary figure $\mathrm{S} 1$ ).

Figure 4: Retrogradely labelled sympathetic neurons innervating adipose tissue are found in the parapyramidal region of the rostroventral medulla, as are chemogenetically activated locomotor and sympathetic vasomotor neurons. A. Illustration modified with permission from Adler et al., 2012 (py: pyramids, gm: grey matter, wm: white matter). B. Modified with permission from Armstrong et al. 2017. Figure 4B2 was taken with increased exposure time to maximize visualization of genetically modified cells at low power. Full version is in supplemental materials (supplementary figure S2). 


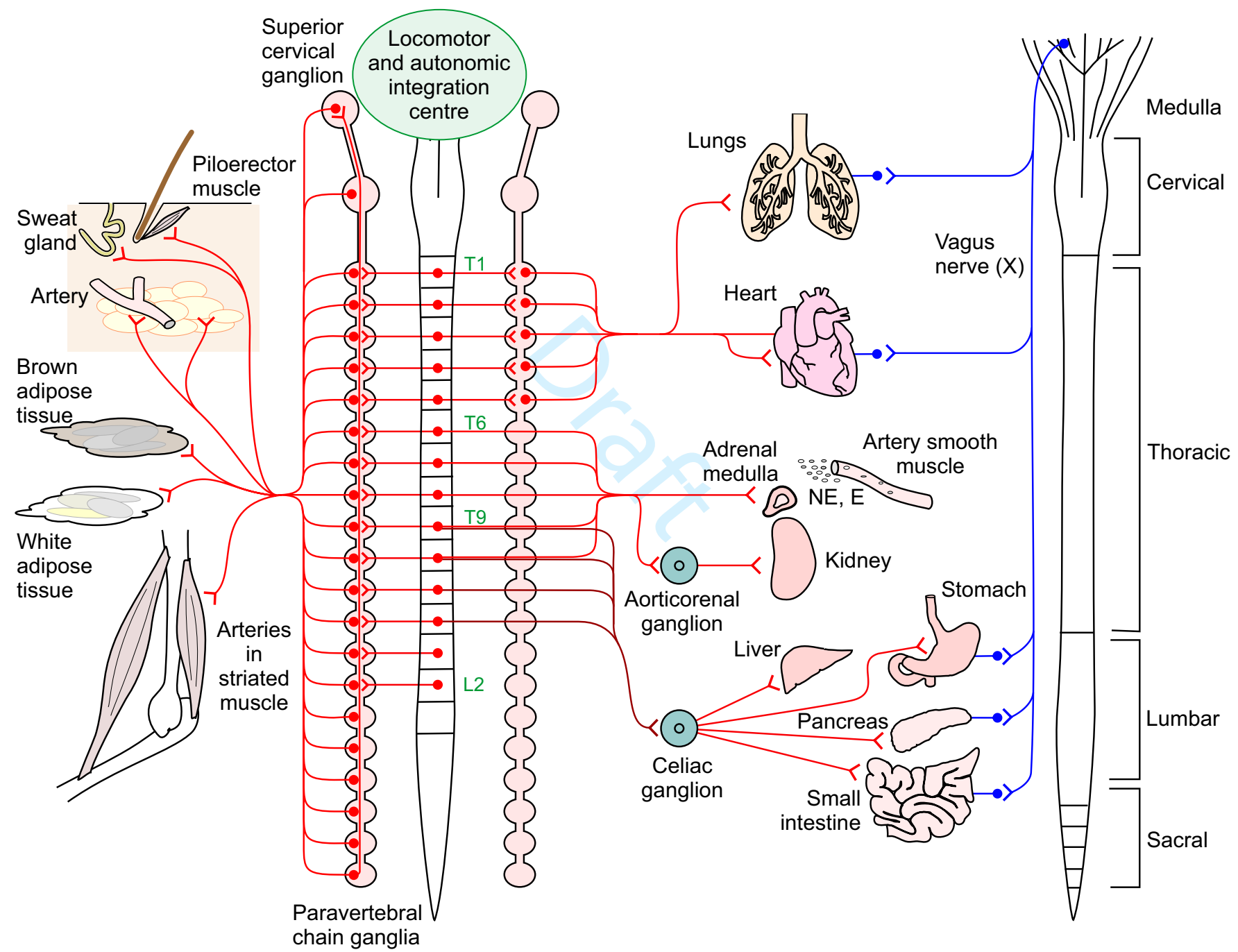


Medullary spinal control centre for integrating sympathetic autonomic support to sustain locomotor rhythm production

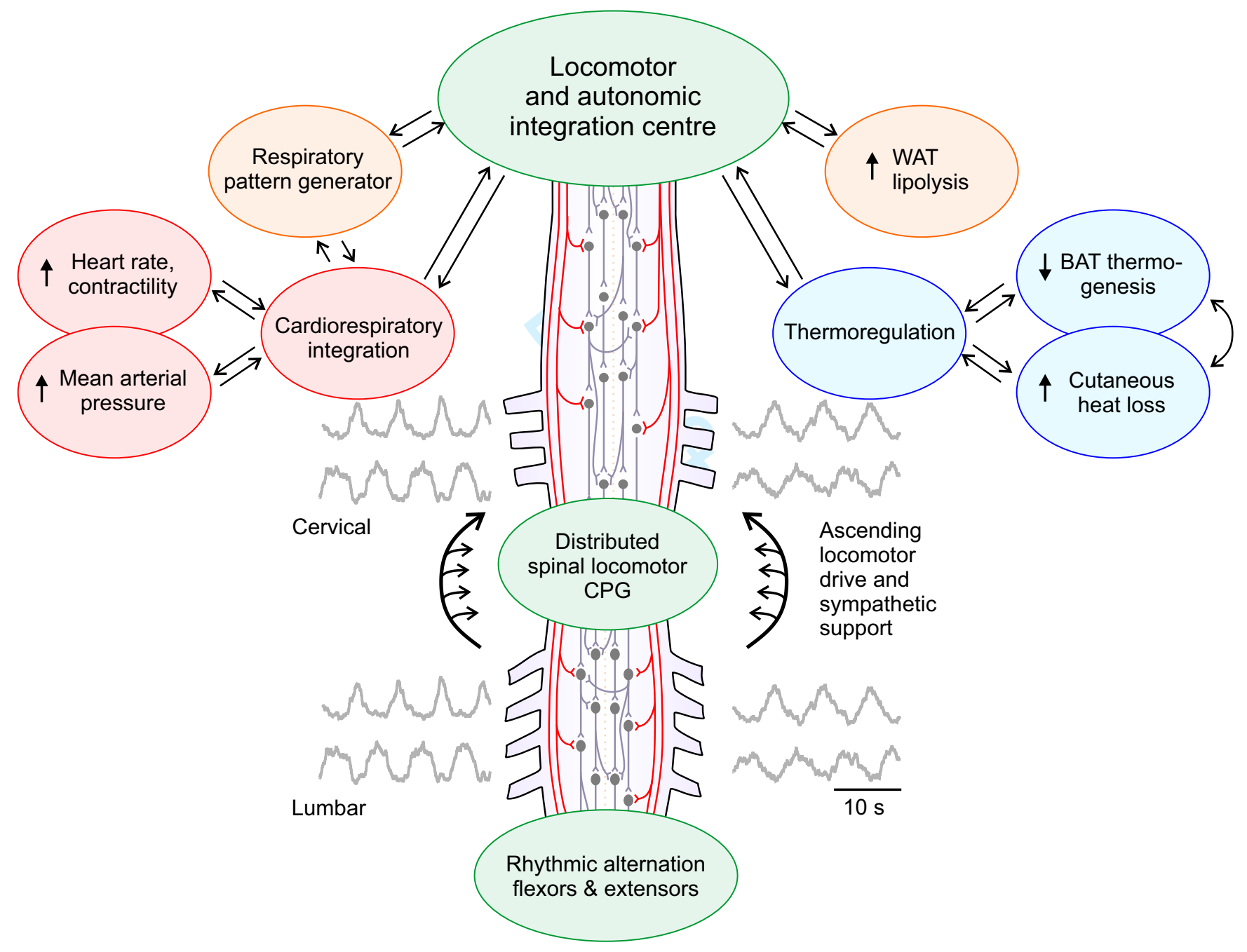




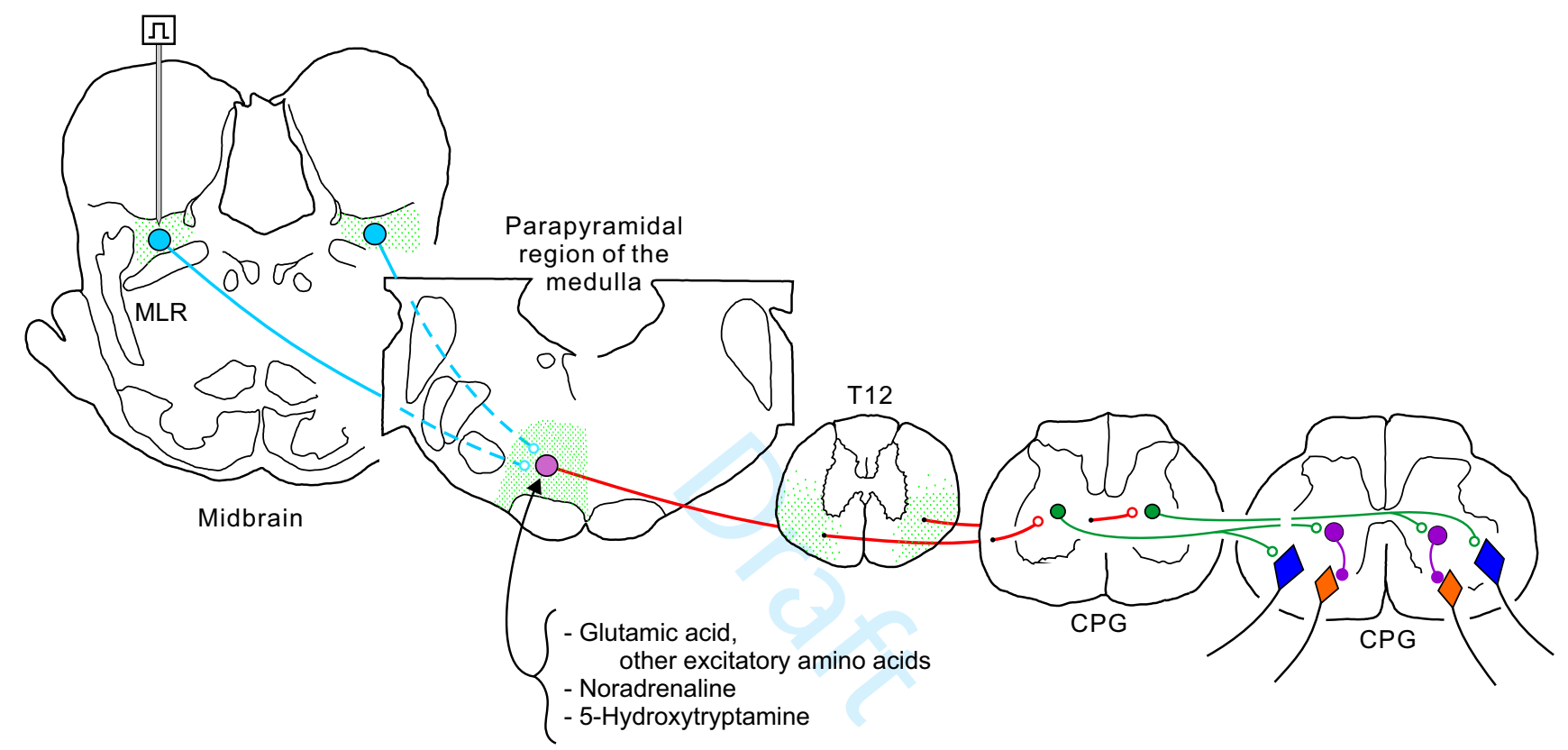



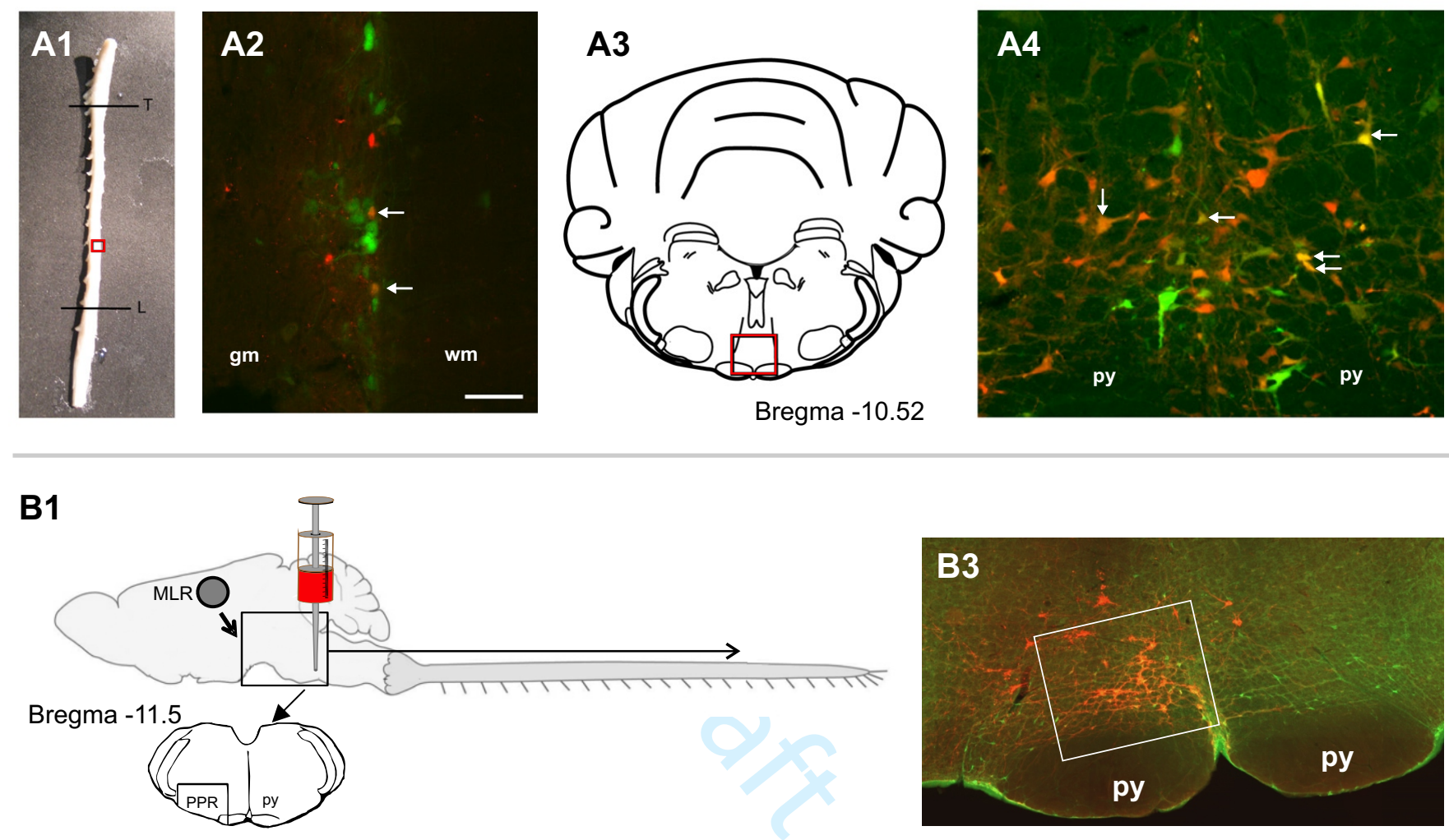

\section{B2}
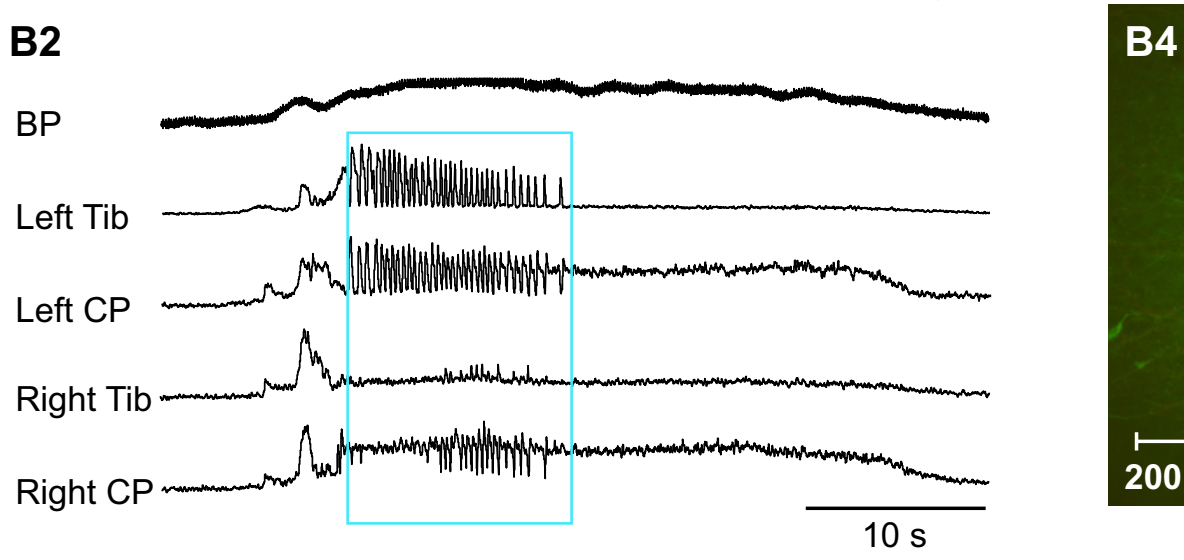